\title{
HETEROGENEITY OF UBIQUINONE SYSTEMS IN THE GENUS SPOROTHRIX
}

\author{
MOTOFUMI SUZUKI AND TAKASHI NAKASE \\ Japan Collection of Microorganisms, The Institute of Physical and \\ Chemical Research (RIKEN), Wako, Saitama 351-01, Japan
}

(Received April 1, 1986)

The genus Sporothrix Hektoen and Perkins is a group of little-differentiated Hyphomycetes. The conidia are non-catenulate or catenulate without marked differentiation of conidia of the first and second order $(1,2)$. WEIJMAN and DE Hoog (3) pointed out that this genus was heterogeneous, containing fungi of hemiascomycetous, ascomycetous and basidiomycetous relationships, based on carbohydrate patterns of whole cells. They divided the members of the genus into three sections, i.e., Sporothrix sect. Sporothrix, Sporothrix sect. Farinosa Weijman and de Hoog and Sporothrix sect. Luteoalba Weijman and de Hoog. SMITH and BatenburG-VAN DER Vegte(4) also pointed out the heterogeneity of the genus Sporothrix on the basis of the ultrastructure of septa. Their results supported the proposition of the WeIJMAN and DE HoOG (3).

The ubiquinone (coenzyme Q) system has been proposed as a useful criterion for classifying yeasts and yeast-like fungi at the generic level(5-8). KurAisHI et al. (9) reported ubiquinone systems of many species in higher fungi and stated that the ubiquinone system was very useful in the classification of fungal taxa and in the elucidation of their genealogy. Until now, however, no information about the ubiquinone systems in the genus Sporothrix is available. We report on these systems here.

Fourteen strains of Sporothrix and Stephanoascus species were used in this study (Table 1). All strains except one were cultivated in YM broth supplemented $2 \%$ of glucose with shaking for 4 to 6 days at 25 or $28^{\circ}$ C. Stephanoascus farinosus JCM 2935 was cultivated for 6 days at $17^{\circ} \mathrm{C}$. Cells harvested by centrifugation $(6,000 \mathrm{rpm}, 20 \mathrm{~min})$ were washed twice with deionized water. Extraction and isolation of ubiquinones from cells were carried out according to the method described by YAMADA and KONDO(5), with a slight modification. Wet packed cells $(5-10 \mathrm{~g})$ were saponified with methanol-sodium hydroxide-pyrogallol $(80 \mathrm{ml}, 8 \mathrm{~g}$, 
Table 1. Ubiquinone systems of Sporothrix species and related species.

\begin{tabular}{|c|c|c|c|c|c|c|c|}
\hline \multirow{2}{*}{ Section and species } & \multirow{2}{*}{ Strain } & \multirow{2}{*}{$\begin{array}{c}\text { Other } \\
\text { designation }\end{array}$} & \multicolumn{5}{|c|}{$\begin{array}{l}\text { Molar ratio of ubiquinone } \\
\text { isoprenologues }(\% /)^{a}\end{array}$} \\
\hline & & & Q-8 & Q-9 & Q-9 $\left(\mathrm{H}_{2}\right)$ & Q-10 & Q-10( $\left(\mathrm{H}_{2}\right)$ \\
\hline \multicolumn{8}{|l|}{ Sporothrix sect. Sporothrix } \\
\hline Sporothrix curviconia & JCM $2922^{b}$ & CBS 959.73 & - & 1.0 & 1.6 & $\operatorname{tr}$ & 97.4 \\
\hline Sporothrix inflata & JCM $2920^{b}$ & CBS 239.68 & - & 0.9 & 2.2 & 0.6 & 96.2 \\
\hline Sporothrix schenckii & JCM 2915 & CBS 359.36 & - & - & 1.4 & 0.7 & 97.9 \\
\hline \multicolumn{8}{|l|}{ Sporothrix sect. Farinosa } \\
\hline Sporothrix ghanensis & JCM 2925 & CBS 769.73 & - & - & $\operatorname{tr}$ & 3.1 & 96.9 \\
\hline Sporothrix insectorum & $\mathrm{JCM} 2918^{b}$ & CBS 756.73 & - & - & 3.8 & 1.3 & 94.9 \\
\hline Sporothrix ranii & $\mathrm{JCM} 2917^{b}$ & CBS 119.81 & - & - & 1.5 & 0.4 & 98.1 \\
\hline Sporothrix sclerotialis & $\mathrm{JCM} 2913^{b}$ & CBS 312.77 & - & 0.6 & 3.2 & $\operatorname{tr}$ & 96.2 \\
\hline Sporothrix catenata & JCM $2921^{b}$ & CBS 215.79 & 3.8 & 95.0 & $\ldots$ & 1.2 & - \\
\hline Sporothrix foliorum & $\mathrm{JCM} 2916^{b}$ & CBS 326.37 & 6.7 & 92.4 & - & 0.9 & - \\
\hline Sporothrix fungorum & JCM $2924^{b}$ & CBS 259.70 & 8.2 & 91.3 & - & 0.5 & - \\
\hline Sporothrix guttuliformis & $\mathrm{JCM} 2919^{b}$ & CBS 437.76 & 9.1 & 90.2 & - & 0.7 & - \\
\hline \multicolumn{8}{|l|}{ Sporothrix sect. Luteoalba } \\
\hline Sporothrix cyanescens & JCM $2914^{b}$ & CBS 357.73 & - & 15.0 & - & 85.0 & - \\
\hline Sporothrix luteoalba & JCM $2923^{b}$ & CBS 209.48 & - & 14.1 & - & 85.9 & - \\
\hline Stephanoascus farinosus & $\mathrm{JCM} 2935^{b}$ & CBS 140.71 & 7.0 & 91.7 & - & 1.3 & - \\
\hline
\end{tabular}

a $\operatorname{tr}$, trace amount; - , not detected.

b Type culture.

Abbreviations: JCM, Japan Collection of Microorganisms (RIKEN), Wako, Saitama, Japan; CBS, Centraalbureau voor Schimmelcultures, Baarn, The Netherlands.

$1 \mathrm{~g}$, respectively) at $75^{\circ} \mathrm{C}$ for $1 \mathrm{hr}$. Ubiquinones were extracted with hexane and isolated by preparative thin layer chromatography using Merck Kieselgel $60 \mathrm{~F}_{254}$ plates $(0.5 \mathrm{~mm}, 20 \times 20 \mathrm{~cm})$ with benzene as the solvent system. Ubiquinone isoprenologues were identified by high performance liquid chromatography (HPLC) by comparing their retention times with those of standard ubiquinones from Q-6 to Q-10 and Q-10 $\left(\mathrm{H}_{2}\right)$. Q-9 $\left(\mathrm{H}_{2}\right)$ was identified based on the equivalent number of the isoprene units (ENIU) values described by TAMAOKA et al. (10). HPLC was performed on a LC-6A liquid chromatograph (Shimadzu) fitted with a Zorbax ODS column $(4.6 \mathrm{~mm} \times 25 \mathrm{~cm})$. Ubiquinone isoprenologues were eluted with a mobile phase of methanol-propan-2-ol $(2: 1, \mathrm{v} / \mathrm{v})$ at $2.0 \mathrm{ml} / \mathrm{min}$, and monitored at $275 \mathrm{~nm}$. Standard ubiquinone isoprenologues, except for Q-8 and Q$10\left(\mathrm{H}_{2}\right)$, were purchased from Sigma Chemical Co. (U.S.A.). Q-8 and Q-10 $\left(\mathrm{H}_{2}\right)$ were prepared from Citeromyces matritensis JCM 2333 and Rhodotorula hasegawae JCM 1545, respectively.

The results are summarized in Table 1. The Sporothrix species had Q-9, Q-10 and Q-10 $\left(\mathrm{H}_{2}\right)$ as the major ubiquinones.

S. curviconia, S. inflata and S. schenckii, in Sporothrix sect. Sporothrix, had Q- 
$10\left(\mathrm{H}_{2}\right)$ as the major component and Q-9, Q-9 $\left(\mathrm{H}_{2}\right)$ and Q-10 as minor components. Q-10 $\left(\mathrm{H}_{2}\right)$ constituted $96.2-97.9 \%$ of the quinones in each species, and Q-9, Q-9 $\left(\mathrm{H}_{2}\right)$ and Q-10 constituted $2.2 \%$ or less. It has been suggested that these species are closely related to species in the ascomycete genus Ophiostoma (3). KURAISHI et al.(9) reported that Ceratocystis piceae IFO 8662 ( $=$ Ophiostoma piceae) had Q-10 $\left(\mathrm{H}_{2}\right)$. The ubiquinone system may also support the relationship between them.

Species assigned to Sporothrix sect. Farinosa were divided into two groups based on the ubiquinone system. S. catenata, S. foliorum, S. fungorum and $S$. guttuliformis had Q-9 as the major component which occupied $90.2-95.0 \%$ of the total quinones. The minor components, Q-8 and Q-10, occupied 3.8-9.1\% and 0.5$1.2 \%$, respectively. S. catenata, the type species of Sporothrix sect. Farinosa, is regarded as the anamorph of Stephanoascus ciferrii(11). Yamada and Smith (8) reported that Stephanoascus ciferrii had Q-9. Stephanoascus farinosus, another species of the genus Stephanoascus (2), also had Q-9 as the major component. S. fungorum, S. guttuliformis, Stephanoascus ciferrii and Stephanoascus farinosus have septa with either one central micropore or several scattered micropores(4). Therefore, these species with Q-9 may have a close relation to the genus Stephanoascus or other hemiascomycetous fungi. S. ghanensis, S. insectorum, S. ranii and $S$. sclerotialis had Q-10 $\left(\mathrm{H}_{2}\right)$ as the major ubiquinone. It occupied $94.9-98.1 \%$ of the total quinones, and Q- $9\left(\mathrm{H}_{2}\right)$ and Q-10, the minor ubiquinones, constituted 3.8 and $3.1 \%$ or less, respectively. Another minor component, Q-9, was detected only in S. sclerotialis. Species with Q-10 $\left(\mathrm{H}_{2}\right)$ may be related to ascomycetous fungi because hydrogenated ubiquinones are also present in various taxa in the Ascomycotina (9). According to de Hoog (personal communication), these species are not endomycetous- but ascomycetous-related. Investigation of ultrastructures of septa of species with Q-10 $\left(\mathrm{H}_{2}\right)$ is needed to further elucidate the phylogenetic relationship of this group of Sporothrix.

$S$. luteoalba and $S$. cyanescens, which were assigned to Sporothrix sect. Luteoalba, had Q-10 as the major component and Q-9 as the minor component. In S. luteoalba, Q-9 and Q-10 occupied 14.1 and $85.9 \%$, respectively. In the latter, Q-9 and Q-10 constituted 15.0 and $85.0 \%$ of the systems, respectively. This section is characterized by the presence of xylose in the cell wall and septa with dolipore as markers of basidiomycete affinity, though $S$. cyanescens lacked xylose in the cell wall $(3,4)$. Since the ubiquinone systems of basidiomycetous fungi are either Q-9 or Q-10(9), these species may have a relation to basidiomycetous fungi having Q-10. Weijman and DE HoOG (3) stated that S. luteoalba resembled cultural states of some Dacrymyces species. KURAISHI et al. (9) reported that Dacrymyces sp. had Q-10.

As mentioned above, the genus Sporothrix is heterogeneous with respect to the ubiquinone system. In addition to the carbohydrate patterns, septal pore ultrastructure, and ubiquinone system, other molecular approaches may be required to clarify the classification of the genus Sporothrix. 
his invaluable suggestions for the present study and his supply of cultures.

\section{REFERENCES}

1) G. S. DE HoOG, Stud. Mycol., 7, 1 (1974).

2) G. S. DE Hoog, A. H. Rantio-Lehtimäkı, and M. Th. Smith, Antonie van Leeuwenhoek; J. Microbiol., 51, 79 (1985).

3) A. C. M. Weijman and G. S. DE Hoog, Antonie van Leeuwenhoek; J. Microbiol., 51, 111 (1985).

4) M. Th. Smith and W. H. Batenburg-Van der Vegte, Antonie van Leeuwenhoek; J. Microbiol., 51, 121 (1985).

5) Y. Yamada and K. Kondo, J. Gen. Appl. Microbiol., 19, 59 (1973).

6) Y. Yamada, M. Nojiri, M. Matsuyama, and K. Kondo, J. Gen. Appl. Microbiol., 22, 325 (1976).

7) Y. Yamada, T. Ohishi, and K. Kondo, J. Gen. Appl. Microbiol., 29, 51 (1983).

8) Y. Yamada and M. Th. Smith, Trans. mycol. Soc. Jpn., 26, 247 (1985).

9) H. Kuraishi, Y. Katayama-Fujimura, J. Sugiyama, and T. Yokoyama, Trans. mycol. Soc. Jpn., 26, 383 (1985).

10) J. Tamaoka, Y. Katayama-Fujimura, and H. Kuraishi, J. Appl. Bacteriol., 54, 31 (1983).

11) M. Th. Smith, J. P. van Der Walt, and E. Johannsen, Antonie van Leeuwenhoek; J. Microbiol. Serol., 42, 119 (1976). 